\title{
OPINIÃO PÚBLICA SOBRE A LIDERANÇA DAS MULHERES EM CARGOS POLÍTICOS: UMA ANÁLISE A PARTIR DE SURVEY'S APLICADOS PELO LAPOP ENTRE 2008 E 2018
}

\author{
Gabriela Catarina Canal ${ }^{1}$
}

Naiara Sandi de Almeida Alcantara ${ }^{2}$

\begin{abstract}
Resumo
Esse artigo tem como objetivo analisar o comportamento de brasileiros e brasileiras na última década em relação à participação das mulheres na política. Utilizamos a metodologia quantitativa de análise e manipulação de Survey's aplicados pelo Latin American Public Opinion Project (LAPOP) entre os anos de 2008 e 2018, para responder a seguinte questão: os brasileiros acreditam que as mulheres são piores líderes políticas? Para tanto, foi realizada uma análise longitudinal de toda a série histórica de aplicação do LAPOP, a fim de verificar se há mudanças de comportamento social. Como objetivo secundário, buscou-se averiguar se existe correlação entre o gênero do/a entrevistado/a e a variável dependente. Parte-se da hipótese de que as mulheres historicamente possuem espaço diminuto em relação aos homens na política, por isso quando ocupam cargos de liderança são consideradas menos capazes que os indivíduos do sexo masculino. Essa hipótese respalda-se, por exemplo, na concepção de Rita Laura Segato (2006), para quem as relações de poder são responsáveis pela substancial desigualdade entre homens e mulheres, bem como, na opinião pública expressa pelos Meios de Comunicação de Massa (MCM). Diante das hipóteses e objetivos elencados, o artigo foi organizado da seguinte forma: inicialmente, é feita uma breve retomada da teoria que demonstra como se constituiu a dominação dos homens sobre as mulheres, relegando a estas uma posição de desprivilegio social que se reflete em todos os âmbitos sociais, inclusive na política. Posteriormente, apresenta-se um retrato das mulheres na política traçados pelos MCM, seguida pela apresentação da metodologia e dos resultados. Verificou-se que, de maneira geral, brasileiros/as acreditam que os homens não são melhores líderes políticos que as mulheres em todos os anos analisados, além disso, não houve mudanças significativas ao longo da década. Todavia, percebeu-se que são sempre os homens quem acreditam que as mulheres são piores líderes políticas, desmistificando assim a ideia do senso comum de que as mulheres não acreditam politicamente em outras mulheres.
\end{abstract}

Palavras-Chave: Mulheres; Política; Opinião pública; Liderança feminina.

\footnotetext{
${ }^{1}$ Bacharela em Direito pela Universidade Estadual de Maringá (UEM). Pós-graduanda em Direito e Processo Penal pela Academia Brasileira de Direito Constitucional (ABDConst), e-mail: gabrielacatarina11@gmail.com. ORCID: https://orcid.org/0000-0001-7622-667X?lang=en

${ }^{2}$ Mestra em Ciências Sociais pela Universidade Estadual de Maringá (UEM). Doutoranda em Ciência Política pela Universidade Federal do Paraná (UFPR), e-mail: nayara_sandy@hotmail.com. ORCID: https://orcid.org/0000-00033343-5097
} 


\section{INSERÇÃO E PRESENÇA DAS MULHERES NA POLÍTICA}

O movimento feminista nacional foi influenciado pelo movimento das "suffragettes" que teve início no Reino Unido no século XIX, mas no Brasil é só a partir de 1900 que a luta feminista torna-se mais ávida, através da atuação de Berta Lutz aliada a Maria Lacerda de Moura, que, em 1918, criou a Liga de Emancipação Intelectual da Mulher, a qual passou a ser denominada como Federação pelo Progresso Feminino em 1919. Nesse mesmo ano, o Senador Justo Chermont apresentou um projeto de lei que estenderia o direito de voto às mulheres, mas o projeto não obteve aprovação (ARAÚJO, 2001).

Os anos seguintes compuseram-se de lutas e criações de movimentos aliados, todavia, foi somente com o Código Eleitoral de 1932 que as mulheres se tornaram eleitoras, cuja previsão encontra-se no artigo $2^{\circ}$ do referido diploma legal: "É eleitor o cidadão maior de 21 anos, sem distinção de sexo, alistado na forma deste Código" (Decreto no 21.076 de 24 de Fevereiro de 1932).

Cabe salientar que o Brasil estava passando por inúmeros processos revolucionários, com um governo nacional desenvolvimentista, e metade da população ainda não possuía direito ao voto. As mulheres ativas na luta feminista conclamavam o direito de participação política, alegando que sua função enquanto sujeito feminino não deveria se restringir à procriação. Destaca-se que, nesse período, apenas um grupo restrito de mulheres conseguia participar das lutas feministas, aquelas pertencentes à classe social alta, deixando de fora trabalhadoras e mulheres negras (ARAÚJO, 2003).

Segundo Prá (2011), mesmo após adquirirem o direito de votarem e serem votadas as mulheres não conseguiram acessar o espaço político, permanecendo na sub-representação. Isso ocorreu porque os contratos eram firmados por homens, por isso, não possuíam apenas cunho social, mas também cunho sexista, com intuito de promover a manutenção do poder patriarcal em que a mulher é submissa ao homem. Neste sentido, houve um momento de reconhecimento do voto feminino, contudo, não ocasionou um aumento da participação feminina na política, pois, conforme Prá (2011) na maior parte do mundo as mulheres ainda são minoria na política.

Segundo a Estatística da União Interparlamentar (2011), o Brasil ocupa o $108^{\circ}$ lugar no ranking de participação política das mulheres, em relação a 188 países, e na última década esses dados permaneceram estagnados, ou seja, as mulheres não passaram a participar mais do que participavam antes. Os baixos níveis de participação feminina na política se reverberam em outros índices, como no Índice de Desenvolvimento Humano (IDH); se, de maneira geral, ele está 
aumentando, quando se realiza a análise por gênero, percebe-se desigualdades. De acordo com os dados do Índice de Desenvolvimento de Gênero (IDG) e do Índice de Participação segundo Gênero (IPG), a diminuição da desigualdade de gênero implicaria em um consequente aumento do IDH.

Segundo Biroli (2010), as mulheres são subrepresentadas na política por dois motivos: o primeiro é porque em democracias liberais parte-se de uma igualdade entre os gêneros, que na prática não ocorre, e o segundo está relacionado às ocupações das mulheres na sociedade, que em geral são subalternas aos homens, razão pela qual não possuem espaço na política.

É possível afirmar que existem diversas raízes históricas determinantes para a colocação da mulher em uma posição subalterna na sociedade, nos mais variados aspectos de suas vidas, que vão desde as maiores dificuldades de acesso à educação e menores salários em comparação aos homens, até problemas relacionados à violência de gênero e ao assédio e violação sexual. Em uma sequência cronológica, tais raízes remontam a Antiguidade, mais especificamente tradições greco-romanas, as quais inclusive acabaram sendo transportadas para os dispositivos legais, constituindo a base do Direito no mundo ocidental. Neste sentido, Mello (2017) destaca que o Direito tradicionalmente tem sido a forma através da qual o poder dos homens sobre as mulheres se organizou.

Em um clássico estudo sobre a história civil do mundo greco-romano, Coulanges (2002) caracteriza a religião, fundada no culto aos mortos, como o elemento constitutivo da família. Não era o nascimento nem o afeto os responsáveis pela criação de laços familiares, mas sim o poder paterno do homem, enquanto marido sobre a mulher, e como pai sobre o/a(s) filho/a(s), superioridade essa originária da religião do lar e dos antepassados.

No contexto brasileiro, especialmente no tocante à tradição patriarcal desenvolvida no período da colonização, a mulher sempre fora tratada como propriedade, em uma constante relação de submissão: ora do pai, ora do marido. Deveria, portanto, manter-se virgem para assegurar a honra do pai até o casamento, e após este, deveria manter-se fiel para assegurar a honra do marido, sob pena de castigos severos (como privação de alimentos e cárcere privado), enquanto a ele era concedida total liberdade para relacionar-se com outras mulheres (MELLO, 2017).

Apesar disso, as mulheres sempre foram agentes sociais produtivos no mercado de trabalho. Somente após a consolidação da industrialização é que o "lar" enquanto unidade doméstica passou a ser o espaço privado destinado à resignação do sexo feminino, enquanto o discurso hegemônico pregava que o trabalho era realizado somente pelos homens e no espaço público. No período manufatureiro, os homens destinavam-se aos trabalhos no campo, enquanto as mulheres trabalhavam com a manufatura de todos os itens essenciais a reprodução familiar. Antes da criação 
das indústrias, esse tipo de serviço era realizado no interior das casas, mas recebia tanto reconhecimento quanto o trabalho realizado no espaço público (DAVIS, 1982).

Quando o espaço doméstico passou a ser entendido como o local do não trabalho, a mulher perdeu a valorização que recebia enquanto trabalhadora. Passou a ser vista como esposa e mãe, então, restava-lhe somente o cargo de cuidadora, como uma função natural e intrínseca ao sexo feminino. A mulher deixava de prestar um serviço e passava a servir segundo sua obrigação em função de seu sexo. Em razão dessa mudança que desprivilegiava um dos sexos, em 1830 as mulheres passaram a reagir, especialmente as brancas com alto poder aquisitivo, que almejavam aprender e participar do mundo público. Já as mulheres negras ainda se encontravam nas senzalas, embora tenham iniciado também os movimentos em prol da abolição da escravatura (DAVIS, 1982). Ao refletir sobre o tratamento legislativo historicamente dispensado às mulheres, caracterizado por uma eminente desigualdade, tem-se que o próprio sistema legal foi constituído sob o lastro da dominação masculina, o que certamente foi transposto para o aspecto político, pois apesar dos esforços dos movimentos feministas e de mulheres, desde a luta pelo sufrágio universal, os efeitos desta organização social que privilegia homens em detrimento das mulheres foram tão nocivos que acabaram criando uma discrepância significativa em relação ao acesso aos cargos públicos e de liderança, que ainda está longe de ser superada, especialmente no que diz respeito à política.

Tendo em vista essa discrepância entre gêneros no âmbito político, pretendeu-se através da análise de dados que demonstram essa diminuta participação feminina, entender em que medida isso se reflete na opinião pública dos brasileiros, e utilizando do banco de dados do LAPOP, responder se os brasileiros acreditam que as mulheres são piores líderes políticas que os homens ${ }^{3}$. Ademais, essa análise foi feita de maneira longitudinal, para que todas as rodadas de aplicação do LAPOP que contêm a variável dependente (VB50. Em geral, os homens são melhores líderes políticos que as mulheres $)^{4}$, medida em uma escala de quatro pontos, em que 1 significava discorda

\footnotetext{
${ }^{3}$ Utilizamos a questão de pesquisa escrita dessa forma porque é assim que se encontra o enunciado da variável que estamos utilizando como dependente na pesquisa. Salientamos que o material empírico foi fornecido pelo Latin American Public Opinion Project (LAPOP), entendemos que os Surveys podem apresentar problemas em determinadas variáveis, como o viés de ancoragem, isso é, quando uma pergunta tende a pré-determinar a resposta do entrevistado, todavia trata-se de uma pesquisa com tradição de aplicação de questionários de opinião públicas, com cerca de sete rodadas no Brasil, ademais seus dados são representativos do $\mathrm{N}$ total de brasileiros. Como não temos outro material empírico nacional para avaliarmos a questão que nos propomos a tratar, decidimos utilizer o LAPOP. A nosso favor argumentamos que os dados disponibilizados por essa organização são largamente utilizados e testados por pesquisadores de diversos países do mundo, especialmente nos EUA, portanto ainda que hajam questões problemáticas, são dados que possuem qualidade.
} 
muito a 4 concorda muito, fossem analisadas, também dividiu-se o banco por gênero, para utilizar o sexo do entrevistado como variável dependente, a fim de compreender os resultados pelo prisma da divisão entre homens e mulheres.

\section{COTAS NA POLÍTICA E MULHERES NA MÍDIA}

Ao longo dos anos, as mulheres constituíram-se como grupo heterogêneo, mas que lutam por objetivos semelhantes, como inserção na política e autorrepresentação, especialmente dos assuntos que lhes tangenciam. Um dos direitos alcançados foram as cotas para mulheres na política, que de acordo com Prá (2011) funcionam como uma medida paliativa, porque a questão da participação feminina deve ser incutida socialmente e tão somente as cotas na política não são suficientes para gerar participação efetiva. Entretanto, a autora entende que a existência de cotas abre precedentes para outras mudanças em prol deste processo de afirmação enquanto sujeitas da política.

Araújo (2001) afirma que a política de cotas foi uma ação afirmativa dos anos 90 que auxiliou no aumento da participação feminina "quer por iniciativa voluntária dos partidos quer por legislações eleitorais." Todavia, no Brasil quantitativamente a participação feminina ainda é diminuta. Segundo a autora, a política de cotas no Brasil aumentou significativamente a participação feminina no parlamento que foi de 6,15\% nas eleições de 1994 para 10,35\% após a implementação das cotas em 1998, contudo, não alcançou nem metade da meta estabelecida para a participação feminina, que é de $25 \%$.

Movimento semelhante ocorreu nas Assembleias Legislativas dos entes federativos: houve aumento significativo de 1994 (7,2\%) para 1998 (12\%), mas também distante da meta de 25\%. Há diversos motivos, segundo Araújo (2001), para a difícil inclusão das mulheres na política, sendo um deles a resistência que os partidos possuem em aceitarem a inserção de mulheres na arena política, por mero preconceito e discriminação.

As cotas na política são um instrumento em prol de uma "correção histórica", com a finalidade de garantir um aumento na ocupação de cargos públicos de liderança por mulheres. $\mathrm{O}$ Código Eleitoral Brasileiro - Lei n ${ }^{\circ} 9.504 / 1997$ - prevê, em seu art. $10^{\circ}$, $\S 3^{\circ}$, que cada partido ou coligação preencherá o mínimo de $30 \%$ e o máximo de $70 \%$ para candidaturas de cada sexo. 
Segundo Marques (2018), a legislação eleitoral continha um dispositivo transitório que definia um percentual de $25 \%$ para as eleições gerais de 1998, mas ao contrário do que se esperava, o número de eleitas recuou de 6,2\% na Câmara de Deputados em 1994, em uma eleição sem cotas, para 5,7\% nas eleições de 1998 com cotas e, desde 2002, quando as cotas passaram a ser de 30\%, houve um aumento de eleitas para a Câmara dos Deputados, mas de forma muito fraca.

Ainda segundo Marques (2018), é muito comum ouvir a afirmativa de que "as cotas não funcionam" e esse fracasso demonstrado pelas estatísticas poderia corroborar tal afirmação. Contudo, a autora chama atenção para o entendimento de grande parte da literatura especializada, no sentido de que o problema, no Brasil, não é a política de cotas em si, mas o conjunto de regras eleitorais. Isto porque no Brasil existem as chamadas eleições majoritárias para cargos do executivo e para o Senado, e eleições proporcionais para as Câmeras de Vereadores, Assembleias Legislativas e Câmara dos Deputados, sendo que as cotas de gênero somente se aplicam às proporcionais e, quem ordena a lista é o eleitorado, e não o partido, o que a literatura denomina como "sistema proporcional de lista aberta” (MARQUES, 2018).

Já nos "sistemas proporcionais de lista fechada", as listas de candidaturas são pré-ordenadas, previamente definidas pelos partidos, assim, a competição ocorre entre os partidos e a reserva das vagas previstas em lei são também pré-estabelecidas. No Brasil, no entanto, a lista é ordenada pelos votos recebidos do eleitorado, o que segundo Marques (2018) não indica uma "culpa do eleitorado", que corroboraria a expressão "nem mulher vota em mulher". Para a autora, não há evidência de que o eleitorado não vote em mulheres e o fenômeno estaria muito mais associado à baixa competitividade de suas candidaturas do que em relação ao preconceito contra mulheres e a associação enquanto fracas e menos competentes.

A questão das cotas é problemática no Brasil, por diversos motivos. Um deles é a não existência de lei que obrigue o preenchimento das cotas destinadas às mulheres, então os homens não ocupam esse espaço não preenchido, mas ele permanece em branco. $\mathrm{O}$ segundo motivo que impede a eleição de mulheres está na quantidade de candidatos/as ser muito maior do que a quantidade de vagas, isso é um empecilho para a mudança de atores no poder. Salienta-se que o movimento de mulheres luta pela participação ativa, todavia é importante que as mulheres sejam eleitas, ou seja, ocupem de fato os cargos políticos, e não participem somente do momento de competição eleitoral (ARAÚJO, 2001).

Veja-se, por exemplo, a situação das mulheres negras no Brasil: na esfera econômica, tratase de grupo isolado na base da hierarquia social, e em termos de pobreza e desigualdade de renda, 
recebem aproximadamente $30 \%$ do que auferem os homens brancos. Além disso, mesmo representando $25 \%$ da população nacional, somente treze mulheres autodeclaradas negras ocupam mandados legislativos iniciados em 2019 na Câmara dos Deputados, o que representa apenas 2\% das cadeiras (RIOS, 2019).

Neste sentido, as dinâmicas de discriminação interseccional, sejam elas diretas ou indiretas, isto é, intencionais e não intencionais, são injustas, pois provocam violações de direitos agravadas pela concorrência simultânea de diversos fatores de discriminação, alijando de forma ainda mais intensa certos indivíduos e grupos o reconhecimento, o gozo e o exercício de direitos; fenômeno denominado discriminação múltipla, o que pode ser vislumbrado, principalmente, no âmbito orçamentário em prejuízo de mulheres negras empobrecidas, em especial nos cenários de crise econômica e de austeridade fiscal, justamente em razão da sub-representação no terreno parlamentar, onde é elaborado o orçamento (RIOS, 2019).

A maneira pela qual a grande mídia brasileira veicula notícias relacionadas às mulheres na política, demonstra que as mesmas são constantemente julgadas por suas características individuais, notadamente a personalidade. Biroli (2010) realizou uma análise da veiculação de notícias referentes a três figuras femininas na política - Heloisa Helena, Marta Suplicy e Dilma Rousseff nas seguintes revistas semanais: Veja, Época e Carta Capital, entre os anos de 2006 e 2007 para verificar de que forma eram retratadas, demonstrando que esses espaços midiáticos podem ser tanto de transformação quanto de manutenção das condições a que estão submetidas as mulheres, e o problema é que assim como na política, elas são similarmente sub-representadas nas mídias.

Em geral, as mulheres são muito mais associadas ao seu corpo e à emotividade do que em relação aos demais aspectos, o que não ocorre em relação aos homens. Biroli (2010) salienta que a relação entre a forma como as mulheres são retratadas na mídia e a sub-representação na política não possui uma simples relação causal, pois o processo de entrelaçamento é mais complexo, afinal, tudo parte anteriormente de uma concepção social, isto é, a formação da agenda jornalística advém de um corpo de profissionais que elencam quais são os assuntos de destaque e a maneira de apresentação, esse processo não é neutro, já que produzidos por indivíduos que partem de uma sociedade com suas próprias hierarquias.

Através da manutenção da ordem social já existente, grande parte da mídia utiliza de argumentos de caráter pessoal para naturalizar a não participação feminina na política, como espaço destinado aos homens que, simplesmente por serem do sexo masculino estariam destinados a esfera pública e ao mundo dos negócios, enquanto a mulher deveria se resignar à esfera privada e 
doméstica em razão do seu sexo biológico, como se fosse um item definidor para a geração de pessoas interessadas ou desinteressadas por política (BIROLI, 2010).

No período compreendido entre 2010 e 2016, a Ex-Presidente Dilma Rousseff foi constante e seguidamente caricaturada pela mídia como histérica e desorientada e as suas declarações públicas eram retratadas em tom jocoso, explorando sua dificuldade de comunicação. Neste sentido, é icônica a capa da Revista IstoÉ de abril de 2016, em que Dilma aparece com uma expressão de raiva (boca aberta de forma proeminente, testa franzida, sobrancelhas levantadas), que em letras garrafais anuncia: “As explosões nervosas da Presidente”, sugerindo que a então Presidente apresentava comportamento agressivo, quebrando móveis do Palácio, gritando com subalternos e xingando autoridades, razões pelas quais teria perdido as condições emocionais para conduzir o país (Revista Istoé, 2016).

Influenciados pelas manifestações midiáticas que deterioravam a imagem de Dilma e com a finalidade de criticar a política de preços dos combustíveis à época, uma parte da sociedade passou a demonstrar seu desprezo pela então Presidente, colando nas bombas de abastecimento de seus carros, adesivos que continham uma montagem com a imagem dela, de pernas abertas, de modo a simular, no momento do abastecimento, uma violação sexual, como se fosse uma "punição" pela política de preços vigente no país à época 5 .

O fato é que esse apelo à desmoralização da personalidade e à sexualização da figura pública não ocorre quando o político em questão é homem. Sob a gestão do atual presidente, Jair Bolsonaro, novamente e de forma ainda mais intensa, se tem vivenciado um aumento exponencial no preço dos combustíveis, mas a população não tem se voltado contra essa política com o mesmo fervor, tampouco tem se utilizado dessa forma de expressão, baixa e vulgar. Normalmente, são associadas ao Presidente Bolsonaro as figuras de postos de combustíveis e bombas de abastecimento, mas nunca de forma sexualizada. ${ }^{6}$

Atualmente, a discriminação nos meios de comunicação é mais velada, já que não existem mais espaços institucionalmente destinados a homens e mulheres, ainda assim, isso não garante que as mulheres sejam devidamente representadas. O que Biroli (2010) pretendeu demonstrar é que as mídias podem ser espaços modificadores à medida que proporciona discussão e reflexão pública.

5 Questão de gênero. Adesivos misóginos são a nova moda contra Dilma, 2015. Fonte: <https://revistaforum.com.br/noticias/adesivos-misoginos-sao-nova-moda-contra-dilma/> Acesso em 23 de jan. 2020.

6 Veja-se, por exemplo, a imagem utilizada pelo "Blog do Esmael": <https://www.esmaelmorais.com.br/2019/11/bolsonaro-aumenta-preco-da-gasolina-1-dia-apos-dolar-bater-no-ceu/> e também pelo site "Comunicando Fatos": < https://comunicandofatos.wordpress.com/2019/03/15/bolsonaro-sobe-precoda-gasolina-pela-5a-vez-so-em-marco-de-2019/> Acesso em 14 de jan. 2020. 
Entretanto, para que ocorram mudanças em relação às condições a que mulheres são submetidas, é necessário avaliar a maneira como essas sujeitas são retratadas, pois ainda que a mídia não seja a criadora dos estereótipos sociais, ela pode agir no sentido de desmistificá-los ou então reforçá-los.

Buscando um parâmetro de comparação, Biroli (2010) utilizou a figura do então Ministro da Justiça Márcio Thomaz Bastos, que foi citado pela mídia no mesmo período, em média, tanto quanto as mulheres analisadas, para verificar o que foi dito sobre ele e sobre Helena, Suplicy e Roussef. Destaca-se que mesmo essas mulheres sendo atuantes politicamente, elas não foram citadas majoritariamente nas sessões das revistas destinadas a política. Essas sessões foram compostas por $28,1 \%$ de homens e apenas $14 \%$ por mulheres. As mulheres somente são maioria nas sessões sobre: cidades, educação e faits-divers. ${ }^{7}$

Além disso, ficou evidente que a forma como as revistas retratam as mulheres está diretamente relacionada às suas personalidades, fazendo menção a corporalidade e a vida privada. $\mathrm{Na}$ análise dos casos feitos por Biroli(2010) ora as mulheres são invisibilizadas, ora os estereótipos sociais são reforçados.

Verifica-se, portanto, que historicamente as mulheres estiveram em situação desprivilegiada em relação aos homens, e somente conseguiram obter a possibilidade de votarem e serem votadas há menos de um século. Desde então, possuíram conquistas no âmbito político, como as políticas de cotas, entretanto nem mesmo tais métodos paliativos foram capazes de igualar a participação política em relação aos homens. Diante dessa hierarquia cristalizada em que os homens formam a maior camada da elite política, em que a mídia reforça tais estereótipos, esse artigo pretende demonstrar o que pensam os brasileiros/as a respeito da participação das mulheres na política.

\section{BRASILEIROS/AS ACREDITAM QUE HOMENS SÃO MELHORES LÍDERES POLÍTICOS DO QUE AS MULHERES?}

\subsection{ASPECTOS METODOLÓGICOS}

A partir do cenário de construção social exposto, no qual os espaços profissionais menos privilegiados foram atribuídos às mulheres, esse artigo parte da hipótese de que, além das mulheres terem menos espaço nas carreiras políticas, quando ocupam cargos de liderança são consideradas menos capazes que os homens.

\footnotetext{
${ }^{7}$ Sensacionalistas.
} 
Por isso, tem-se como objetivo principal verificar a opinião de brasileiros/as sobre a liderança feminina na política, além disso, sabe-se que houve mudanças graduais no movimento feminista que geraram ganhos de direitos para as mulheres, portanto, é possível que a opinião pública similarmente tenha se modificado. Assim sendo, realizou-se uma análise longitudinal para verificar se a amostra tornou-se mais ou menos favorável à liderança feminina. Ademais, foram realizados testes utilizando a variável "Q1 sexo" dos/as entrevistados/as, a fim de saber qual dos sexos é mais favorável à liderança das mulheres.

Para responder aos objetivos propostos utilizou-se como variável dependente a VB50 cujo enunciado é: "Alguns dizem que, em geral, os homens são melhores líderes políticos do que as mulheres. O(A) sr./sra concorda muito, concorda, discorda, ou discorda muito?’. Essa variável foi escolhida, pois é a única que se repete nos Survey's aplicados bianualmente pelo Latin American Public Opinion Project (LAPOP) entre os anos de 2008 a 2018, com exceção de 2010, único ano em que a variável não foi repetida, pelo LAPOP, portanto os anos analisados foram: 2008, 2012, 2014, 2016 e 2018.

A amostra de todos os anos analisados é composta por 7.391 entrevistados, e os missing ${ }^{8}$ são valores muito baixos e não foram considerados nas análises. Tendo em vista que a variável dependente é qualitativa ordinal, e a independente é uma variável qualitativa e binária, entendeu-se que o melhor teste para identificar relação entre elas seria o teste de qui-quadrado.

\subsection{RESULTADOS}

Analisando a variável dependente Vb50 em toda série histórica aplicada no Brasil, sobre a opinião dos entrevistados em relação as mulheres na política, se eles concordam ou discordam que os homens são melhores líderes políticos do que as mulheres, conforme gráfico 1, descobriu-se que em todos os anos as porcentagens dos que concordam com essa afirmação é razoavelmente menor do que os que discordam. Isso significa que no Brasil a maioria das pessoas acredita que os homens não são melhores líderes políticos.

$\mathrm{O}$ ano em que a porcentagem daqueles que não acreditam nisso apresentou as maiores porcentagens foi o ano de 2008, com 33,5\% e ainda assim é a menor parcela dos entrevistados, mas sabe-se que existem outras variáveis que não são consideradas, como por exemplo, as respostas socialmente esperadas, especialmente nos casos das entrevistas conduzidas por mulheres.

\footnotetext{
${ }^{8}$ Valores perdidos
} 
Gráfico 1 - Opinião dos brasileiros sobre os homens serem melhores líderes políticos do que as mulheres entre 2008 e 2018

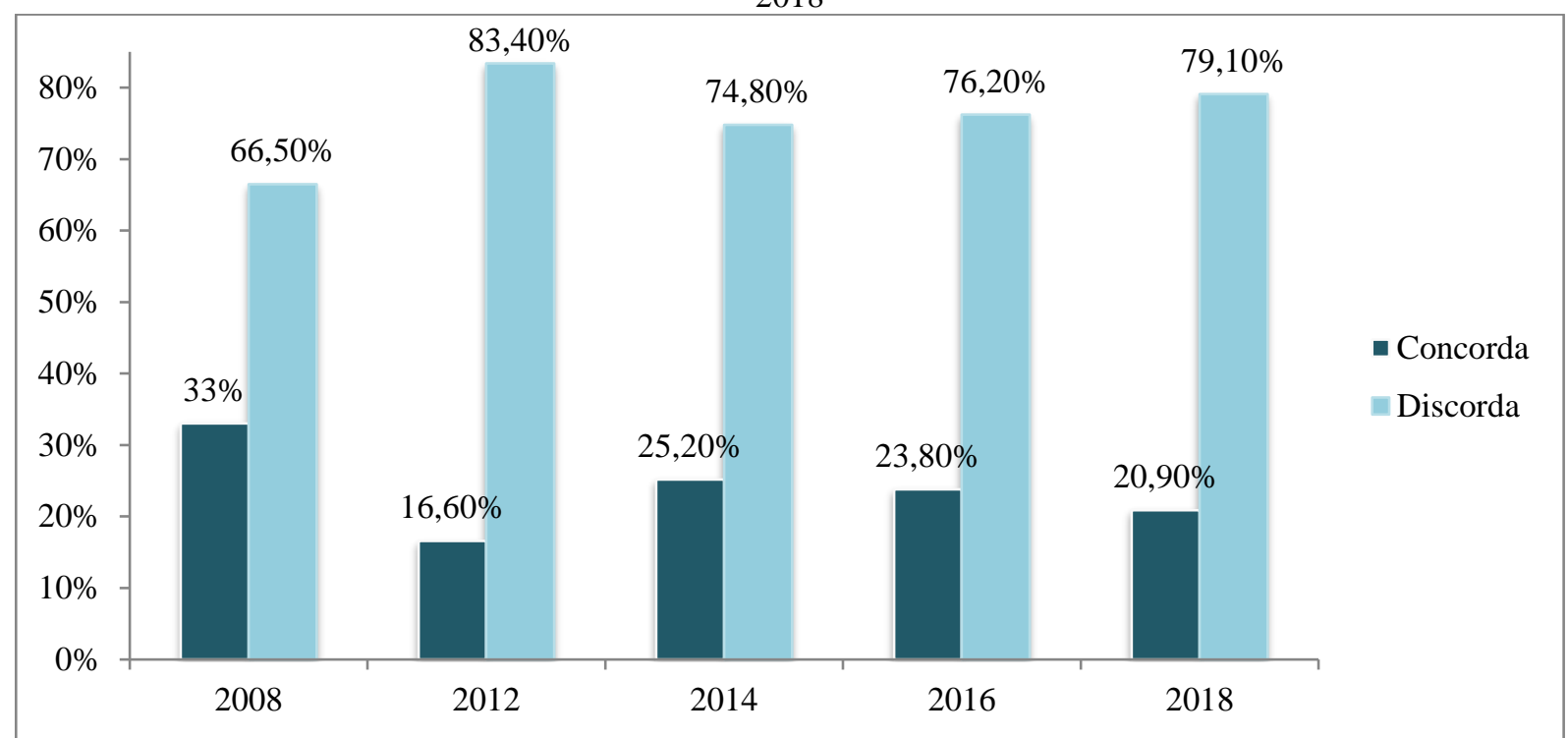

Fonte: Autoras, a partir do LAPOP, 2008, 2012, 2014, 2016 e 2018

Para analisar a relação entre as variáveis dependente e independente, realizou-se o teste de qui-quadrado, que pode ser verificado através da tabela 1 , que demonstra a relação entre sexo do entrevistado e concordar ou não que as mulheres são piores líderes políticas que os homens, porque o valor de $\mathrm{p}$ foi menor que 0,05 , sendo assim escolhemos a hipótese alternativa, ou seja, de que existe associação entre a variável dependente e a independente para o ano de 2008.

Tabela 1-Teste de qui-quadrado entre as variáveis dependente e independente gênero do entrevistado, 2008

Asymp. Sig. (2sided) (valor da

\begin{tabular}{|c|c|c|c|}
\hline & Valor & $\begin{array}{l}\text { df (grau de } \\
\text { liberdade) }\end{array}$ & $\begin{array}{c}\text { significância do } \\
\text { teste) }\end{array}$ \\
\hline $\begin{array}{c}\text { Pearson Chi-Square (Valor do } \\
\text { teste de qui-quadrado) }\end{array}$ & $49,612^{a}$ & 3 &, 000 \\
\hline $\begin{array}{c}\text { Likelihood Ratio (Razão de } \\
\text { verossimilhança) }\end{array}$ & 50,429 & 3 & ,000 \\
\hline $\begin{array}{l}\text { Linear-by-Linear Association } \\
\text { (Associação linear por linear) }\end{array}$ & 47,735 & 1 & , 000 \\
\hline Número de casos válidos & 1437 & & \\
\hline
\end{tabular}

a. 0 celulas $(, 0 \%)$ tem a contagem esperada menor que 5 . O mínimo esperado é 76,81 (pré-requisito)

Fonte: Autoras, a partir do banco do LAPOP 2008

Também se realizou o teste de qui-quadrado para todos os demais anos, mas para não repetir a saída do teste para todos os anos e poupar espaço, montou-se a tabela 2 para apresentar os resultados de interesse (valor do teste e do nível de significância -p). Na tabela 2 é possível 
verificar que para todos os anos existe relação entre as variáveis analisadas, todas os testes também cumpriram os requisitos para a realização do qui-quadrado.

Tabela 2-Resultados dos testes de qui-quadrado realizados para os anos de 2012, 2014, 2016 e 2018, entre a variável Q1 (Sexo do entrevistado) e a variável VB50 (os homens são melhores líderes políticos do que as mulheres).

\begin{tabular}{l|l|l}
\hline Ano & Valor & Nível de significância $(\mathrm{p})$ \\
\hline 2012 & 46.987 & 0,000 \\
\hline 2014 & 49.243 & 0,000 \\
\hline 2016 & 13.106 & 0,004 \\
\hline 2018 & 22.180 & 0,000 \\
\hline \multicolumn{2}{l}{ Fonte: Autoras, a partir dos bancos do LAPOP $(2012,2014,2016$ e 2016) }
\end{tabular}

Tendo em vista a existência de relação entre as variáveis, ou seja, que ser homem ou ser mulher é um fator preponderante em relação a considerar que mulheres são piores líderes políticos que os homens, entendeu-se ser necessário gerar o gráfico 2, para entender qual é a resposta de cada um dos sexos. No gráfico 2, foi possível concluir que existem discrepâncias significativas entre os gêneros, pois os resultados demonstram que são os homens que majoritariamente, em todos os anos, concordam com a afirmativa de que eles são melhores líderes políticos que as mulheres. Deste modo, ainda que a porcentagem de mulheres, em alguns anos, seja quase metade das respondentes que acreditam que os homens são melhores líderes políticos, pode-se inferir que estes acreditam muito mais na falta de potencial das mulheres em serem boas líderes políticas do que elas próprias.

Gráfico 2 - Índice de concordância de que os homens são melhores políticos que mulheres relacionada com o gênero do entrevistado

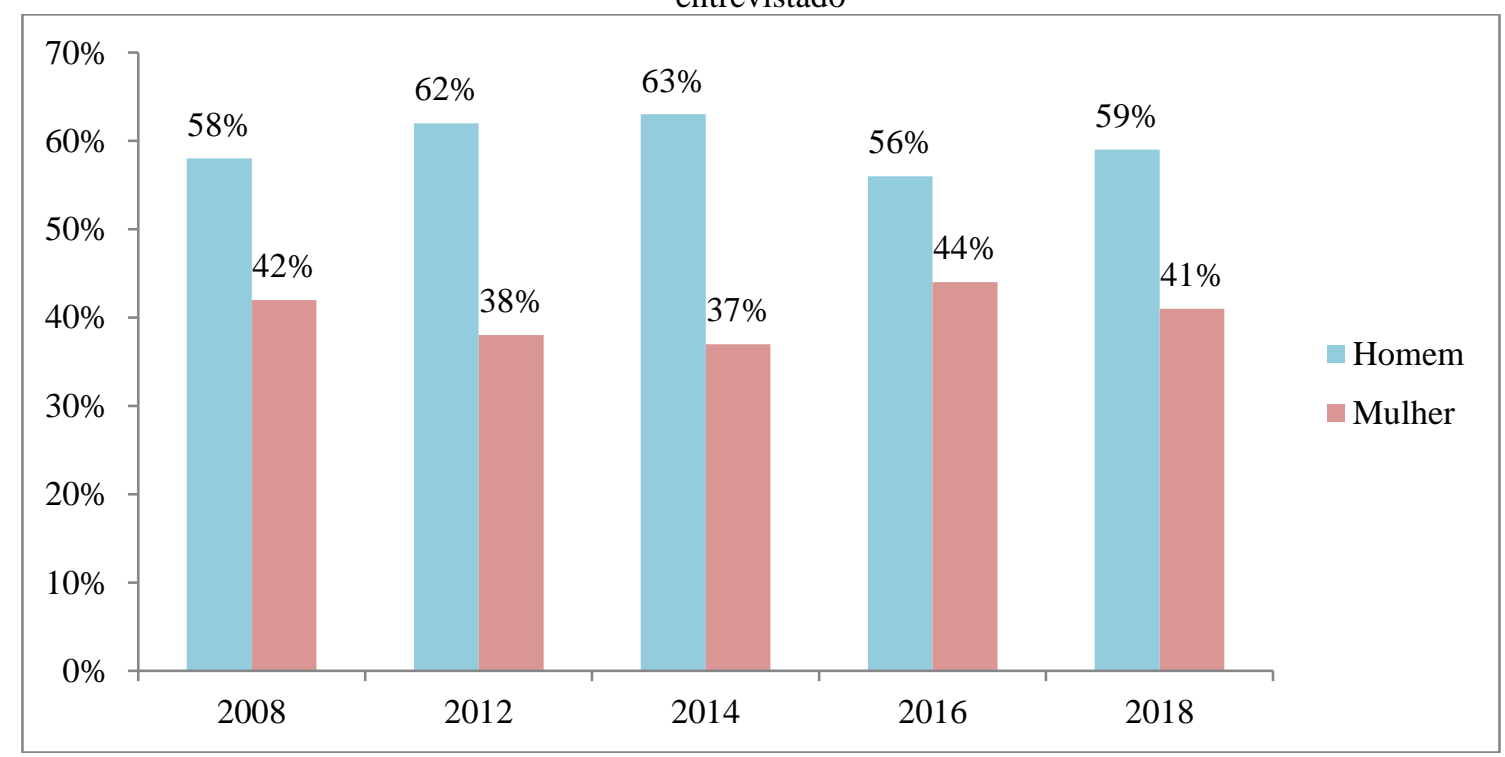

Fonte: Autoras, a partir do LAPOP, 2008, 2012, 2014, 2016 e 2018 
Outro resultado importante é que tanto no primeiro gráfico - em relação à discordância ou concordância de forma geral-, quanto ao segundo gráfico, que mede apenas a concordância entre os sexos, não é possível verificar mudança ao longo dos anos, porque os dados não demonstram um crescimento uníssono em uma única direção, pelo contrário, em todo o período analisado se percebe que as pessoas que compõe a amostra em geral não acreditam que as mulheres sejam inferiores politicamente aos homens, e que eles são melhores líderes políticos, esse resultado varia pouco percentualmente ao longo da série histórica.

Infere-se então que a hipótese de pesquisa foi negada quando se observam as repostas de maneira geral, conforme proposto, pois em média 74,6\% da população acredita que os homens não são melhores líderes políticos que as mulheres. Por outro lado, quando a variável dependente foi analisada separada pelo sexo, nota-se que são os indivíduos de sexo masculino quem sempre consideraram e, permanecem considerando as mulheres piores líderes políticas, e que as porcentagens também se alteram de maneira mínima ao longo da década analisada, portanto não há variação considerável entre os anos.

Isso significa que as mulheres obtiveram ganhos políticos, todavia, isso não se refletiu significativamente na opinião de brasileiros/as, especialmente entre os homens. Porque ainda que os resultados apresentados demonstrem um cenário positivo, já que a média das pessoas que acreditam na igualdade entre os sexos é alta, as porcentagens entre os anos não seguem um padrão crescente. Existe um aumento significativo entre os anos de 2008 (66,5\%) para o ano de $2012(83,4 \%)$, posteriormente, houve um decréscimo $(74,8 \%)$ e os anos que se seguiram foram marcados por pequenos aumentos, mas que estão dentro da margem de erro. Portanto, em média, aproximadamente $25 \%$ da amostra ainda acredita que homens são melhores líderes políticos que as mulheres, sendo que essa crença é baseada tão somente no argumento de que homens, em razão do seu sexo biológico, possuem características intrínsecas (racionalidade, virilidade e afins) que os tornam líderes melhores no âmbito político, ou seja, uma visão inegavelmente machista.

\section{CONSIDERAÇÕES FINAIS}

Os resultados dessa pesquisa corroboram a ideia de que ainda há, no imaginário social, a concepção de uma inferioridade da mulher em relação ao homem quando se trata de política, 
mesmo ante a negativa da hipótese inicial, que considerava que a maioria dos/as entrevistados/as concordariam que mulheres são piores líderes políticas do que os homens.

Como visto, em relação a afirmativa: "homens são melhores líderes políticos do que mulheres", constatou-se que em todos os anos de aplicação do questionário, a porcentagem dos que concordam com essa afirmação é relativamente menor do que a dos que discordam, o que revelaria que os brasileiros e brasileiras não realizam um juízo de valor negativo em relação às mulheres na política, negando a hipótese inicial.

É claro, existem diversos fatores que podem interferir na aplicação e resultados de um Survey, como por exemplo, a possibilidade da opinião socialmente aceitável, omitindo sua real opinião ou então, por estarem eventualmente sendo entrevistados/as por uma mulher, o que poderia influenciá-los a opinarem de forma "favorável". Todavia, a segunda parte da análise dos dados apresentou resultados importantes para a finalidade desse artigo. Ao analisar a variável dependente em relação ao gênero dos entrevistados, constatou-se a significância entre as variáveis dependente e independente. Ademais, verificou-se que são os homens quem, majoritariamente - em média 60\% -, julgam as mulheres como piores líderes políticas. Desmitificou-se, portanto, a falsa ideia de que a culpa pela ineficácia das cotas por gênero seria das próprias mulheres, por não apostarem em sua credibilidade e competência política.

Ante o que fora exposto, tem-se que, por questões histórico-sociais, homens e mulheres partem de locais diferentes, sendo estas preteridas em relação àqueles. Neste sentido, para fins de correção de desigualdades criadas pela dominação masculina, são inócuas as medidas que buscam tratamento isonômico, afinal, não há razão para se dispensar tratamento igualitário aos desiguais. São preferíveis, neste sentido, leis, políticas e medidas equitativas, que promovam um equilíbrio entre grupos substancialmente desiguais, como é o caso de homens e mulheres. É justamente sob essa perspectiva, a da equidade, que fora criada a política de cotas, sejam elas sociais, raciais ou para mulheres na política, sendo esta última o foco da presente discussão.

Foi possível constatar que no contexto brasileiro, embora bem intencionada, as cotas de gênero não tem sido eficazes por duas razões: a) a primeira delas é a maneira pela qual a lei trata da política de cotas, permitindo os "sistemas proporcionais de listas abertas" que acabam preterindo as mulheres nas eleições e, também, por não garantir o preenchimento obrigatório das vagas reservadas; b) a segunda, diz respeito a organização e composição eminentemente masculina dos poderes executivo e legislativo, que garantem e promovem a continuidade de velhas práticas em busca da manutenção desta hegemonia do poder político. 
Por fim, é imperioso destacar que os dispositivos legais referentes às eleições criam empecilhos para a efetivação da política de cotas, na medida em que permite a "burla" ao sistema, o que não ocorre única e exclusivamente por uma falha do legislativo, mas principalmente pela maneira como a política no Brasil consolidou-se e continua sendo conduzida, isto é, majoritariamente composta e comandada por homens, que, conforme demonstrado pela presente pesquisa, continuam a acreditar que são melhores líderes políticos que as mulheres, ao passo que a atuação feminina sempre foi marginalizada. Mais do que garantir a reserva de vagas, é importante concretizar políticas que tornem as candidaturas femininas potentes e competitivas a fim de consolidarem suas carreiras políticas e enquanto lideranças. 


\section{REFERÊNCIAS}

ARAÚJO, Clara. Potencialidades e limites da política de cotas no Brasil. Espaço compartilhadoEstudos feministas, n. 9, 2001, p. 231-252. Disponível em: http://www.scielo.br/pdf/ref/v9n1/8613.pdf Acesso em: 13 de jan. de 2020.

ARAÚJO, Rita de Cássia Barbosa. O voto de saias: a Constituinte de 1934 e a participação das mulheres na política. ESTUDOS AVANÇADOS, 17, (49), 2003, p. 133-150.

BIROLI, Flávia. Mulheres e política nas notícias: Estereótipos de gênero e competência política. Revista Crítica de Ciências Sociais, ISSN: 0254-1106, n. 90, 2010, p.45-69.

BRASIL, Decreto no 21.076 de 24 de Fevereiro de 1932. Decreta o Código Eleitoral. Disponível em: $\quad$ https://www2.camara.leg.br/legin/fed/decret/1930-1939/decreto-21076-24-fevereiro-1932507583-publicacaooriginal-1-pe.html> Acesso em 12 de jan. 2020.

COULANGES, Fustel. A Cidade Antiga. Texto integral, série ouro. Coleção Obra Prima de cada Autor. Tradução Jean Melville. Martim Claret, 2002.

DAVIS, Angela. Mulher, Raça e Classe. (1982) Trad. Livre. Plataforma gueto, 2013.

Inter Parliamentary Union (IPU), 2011. Disponível em: http://archive.ipu.org/pdf/publications/SG11_en.pdf. Acesso em: 13 de jan. de 2020

MARQUES, Danusa. O que são as cotas para mulheres na política e qual a sua importância? 13 de set. de 2018. Gênero e Número. Disponível em: 〈http://www.generonumero.media/o-que-sao-ascotas-para-mulheres-na-politica-e-qual-e-sua-importancia/> Acesso em 12 de jan. 2020.

MELLO, Adriana Ramos de. Feminicídio: uma análise sociojurídica da violência contra a mulher no Brasil. $2^{a}$ ed. Rio de Janeiro, LMJ Mundo Jurídico, 2017.

PRÁ, Jussara Reis. Reflexões sobre gênero, mulheres e política. In: PAIVA, Denise (org). Mulheres, política e poder, Goiânia: Cânone Editorial, Fundação de Apoio à Pesquisa do Estado de Goiás, 2011, p. 101-125.

RIOS, Roger Raupp. Discriminação orçamentária interseccional: raça, gênero e pobreza em tempos de austeridade. In: MELLO, Lawrence Estivalet de Mello, CALDAS, Josiane, GEDIEL, José Antônio Peres (org.). Políticas de austeridade e direitos sociais. Curitiba: Editora Kaygangue Ltda., 2019. p. 66-73.

SEGATO, Rita Laura. Que és un feminicídio: notas para un debate emergente. Série Antropologia. Brasília, 2006.

KARAWEJCZYK, Mônica. As suffragettes e a luta pelo voto feminino. História, imagem e narrativas, N. 17, outubro/2013 - ISSN 1808-9895, p. 1-24. 